\title{
A Brief Introduction to The First International Forum on Methodology of Information Ecology ${ }^{\dagger}$
}

\author{
Yixin Zhong \\ Center for Intelligence Science and Technology, School of Computer, Beijing University of Posts and \\ Telecommunications, Beijing 100876, China; zyx@bupt.edu.cn \\ † Presented at the IS4SI 2017 Summit DIGITALISATION FOR A SUSTAINABLE SOCIETY, Gothenburg, \\ Sweden, 12-16 June 2017.
}

Published: 24 July 2017

Having comprehensively investigated the research in the information discipline, we found that there exist numerous mutually isolated theories, but the knowledge about the mutual interrelations was lacking and hence also there is a lack of global theories, principles and common laws of the discipline. These phenomena are obviously a result mainly from the employment of the methodology of mechanical reductionism that seeks and focuses on characteristic constituent parts, neglecting the role of interactions, and context thus assuming that the whole is simply a collection of independent parts.

Due to the methodology of mechanical reductionism, the most fundamental concept for the information discipline, which is the concept of 'information' of course, has been understood from huge number of different research angles and has become a very hard nut to crack on the global level, very difficult to reach the common understanding among disparate theoretical approaches, indicating the immature status of the discipline.

Unlike the mechanical reductionism, the ecological methodology emphasizes in general the interrelations among all parts of an ecosystem and also the interrelation between the ecosystem and its environment. This is complementary to the methodology of mechanical reductionism, and it is hence able to apprehend the knowledge about the interrelations among the parts and between the system and its environment.

Therefore, the International Forum on Methodology of Information Ecology was proposed by the IS4SI China Chapter and was accepted by the organizer of the IS4SI Summit-2017. The purpose of the Forum is to explicitly focus the attention of the academic circles at the methodology shift in information discipline.

The first International Forum on the Methodology of Information Ecology received high response from authors. 31 papers were accepted for oral presentation at the Forum. The Forum consisted of four sections: (1) Information Ecology: Definition and Basic Principles; (2) Philosophical Foundation of Information Ecology; (3) Applications and Achievements; and (4) Panel Discussion and Debate on Information Ecology.

The First International Forum on Methodology of Information Ecology has been very successful and fruitful. As a new methodology in the information discipline, there will naturally be many points that need to be continually studied and debated, but many participants have realized the high importance of information ecology and its decisive role for the future of the study of information.

(C) 2017 by the author. Licensee MDPI, Basel, Switzerland. This article is an open access article distributed under the terms and conditions of the Creative Commons Attribution (CC BY) license (http://creativecommons.org/licenses/by/4.0/). 